\title{
Heat strain in chemical protective clothing in hot-humid environment: Effects of clothing thermal properties
}

\author{
ZHANG Chuan-kun(张传坤) ${ }^{1}$, CHEN Ying(陈莹) ${ }^{2}$, LIANG Guo-jie(梁国杰) ${ }^{1}$, \\ WANG Xin-bo(王馨博) ${ }^{1}$, ZHENG Xiao-hui(郑晓慧) $)^{1 *}$, DING Song-tao(丁松涛) ${ }^{1 *}$ \\ 1. State Key Laboratory of NBC Protection for Civilian, Beijing 100191, China; \\ 2. Beijing Institute of Fashion Technology, Beijing 100029, China
}

(C) Central South University Press and Springer-Verlag GmbH Germany, part of Springer Nature 2021

\begin{abstract}
Heat strain experienced by individuals wearing chemical protective clothing (CPC) is severe and dangerous especially in hot-humid environment. The development of material science and interdisciplinary studies including ergonomics, physiology and heat transfer is urgently required for the reduction of heat strain. The aim of this paper was to study the relationship among clothing thermal properties, physiological responses and environmental conditions. Three kinds of CPC were selected. Eight participants wore CPC and walked $(4 \mathrm{~km} / \mathrm{h}$, two slopes with $5 \%$ and $10 \%)$ on a treadmill in an environment with $(35 \pm 0.5){ }^{\circ} \mathrm{C}$ and $\mathrm{RH}$ of $(60 \pm 5) \%$. Core temperature, mean skin temperature, heart rate, heat storage and tolerance time were recorded and analyzed. Physiological responses were significantly affected by the clothing thermal properties and activity intensity in hot-humid environment. The obtained results can help further development of heat strain model. New materials with lower evaporative resistance and less weight are necessary to release the heat strain in hot-humid environments.
\end{abstract}

Key words: heat strain; chemical protective clothing; thermal insulation; evaporative resistance; hot-humid environment

Cite this article as: ZHANG Chuan-kun, CHEN Ying,LIANG Guo-jie, WANG Xin-bo,ZHENG Xiao-hui,DING Songtao. Heat strain in chemical protective clothing in hot-humidenvironment: Effects of clothing thermal properties[J]. Journal of Central South University, 2021, 28(12): 3654-3665. DOI: https://doi.org/10.1007/s11771-021-4670-5.

\section{Introduction}

In many special fields such as the petroleum, chemical industry and military, chemical protective clothing $(\mathrm{CPC})$ is required to protect human body from the effects of harmful substances in the environment [1-6]. When wearing CPC, evaporation of sweat from the skin surface is restricted [7-9]. The heat generated by human body is difficult to be effectively dissipated, which results in heat stress [10-14]. Excessive heat stress reduces work efficiency, shortens effective working duration time and even causes heat strain $[15,16]$.

There is a trade-off between protective performance and comfort when designing protective clothing. The two main protective mechanisms of CPC are isolation and absorption of toxic substances $[17,18]$. Increasing thickness of the material can improve protective performance. However, it leads to higher thermal insulation, limiting the body heat loss [7] and imposing a heavier burden, resulting in additional energy consumption $[19,20]$. In addition, bulky and heavy CPC can restrict body movement and thereby affect 
ergonomic comfort $[21,22]$. Reducing heat strain requires the interdisciplinary development of materials science, ergonomics, physiology and heat transfer [23-27].

Heat strain prediction models, such as PHS and HSDA, are widely used in public health and military fields to assess human physiological responses under different environmental conditions [28-30]. Although scientific advances have been made in understanding the thermophysiological responses of the human body to various thermal environments, accurate prediction of heat strain in hot-humid environment or wearing special CPC remains a challenge [29, 31-33].

Some studies [34-36] have focused on heat strain when wearing CPC in different environments. In Ref. [34], 15 participants wore CPC and walked for $60 \mathrm{~min}$ at a speed of $93.9 \mathrm{~m} / \mathrm{min}$ and a slope of $4 \%$ in an environment with relative humidity less than $30 \%$ at $23{ }^{\circ} \mathrm{C}$. MONTAIN et al [35] found that full encapsulation in protective clothing reduced physiological tolerance because fully wrapped persons had lower core temperatures when exhausted than partially wrapped persons. XU et al [36] studied the relationship among fabric, CPC and heat strain using an empirical thermoregulatory model. The results showed that the difference is too small to be detected in hot or humid environments, but it does exist [36, 37]. Accordingly, more physiological trials are needed in order to fully understand the heat strain of CPC especially in hot and humid conditions.

This paper studies the heat strain while wearing three kinds of $\mathrm{CPC}$ in hot-humid environment. We selected CPC using different materials to control the thermal insulation, evaporative resistance and weight, so as to ensure that only one influencing factor is different between the two experiments. The observed core and skin temperatures were compared with the predicted values of PHS.

\section{Materials and methods}

\subsection{Experimental scenarios}

Three types of CPC were used in the experiments with the same underwear and footwear. Figure 1 shows the structural design of the CPC.

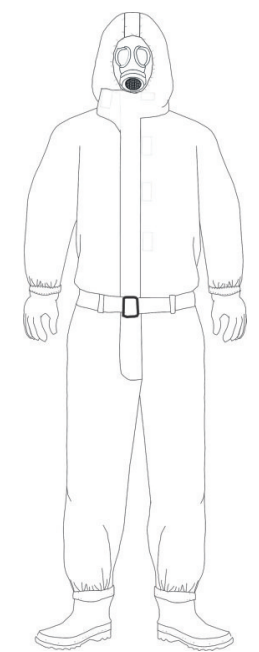

Figure 1 Structural sketch of chemical protective clothing

The main characteristics of clothing materials (CF: cottoned and carbon fabric; PF: polymer membrane coated fabric; RF: rubber composite fabric) are listed in Table 1. The cross-sections of three types of CPC materials are shown in Figure 2. Clothing CF materials have three fabric layers. The fabric layers are very loose and the three layers are not combined seamlessly. Clothing PF materials have two layers. The coating is dense and pore-free. Clothing RF materials have rubber composite fabric. The fabric is embedded into the center of dense rubber and the interface is combined tightly.

The intrinsic thermal insulation $\left(I_{\mathrm{cl}}\right)$ and evaporative resistance $\left(R_{\text {ecl }}\right)$ of chemical protective ensembles were measured in accordance with ASTM F1291 [38] and ASTM F2370 [39] standards, respectively. Determine the intrinsic thermal insulation of the CPC using Eq. (1):

$I_{\mathrm{cl}}=I_{\mathrm{t}}-\frac{I_{\mathrm{a}}}{f_{\mathrm{cl}}}$

where $I_{\mathrm{cl}}$ is the intrinsic thermal insulation (clo); $I_{\mathrm{t}}$ is the total thermal insulation of the CPC (clo); $I_{\mathrm{a}}$ is the thermal insulation of the boundary air layer (clo); and $f_{\mathrm{cl}}$ is the clothing area factor (dimensionless).

Determine the intrinsic evaporative resistance of the CPC $\left(R_{\text {ec }}\right)$ using Eq. (2):

$R_{\text {ecl }}=R_{\text {et }}-\frac{R_{\text {ea }}}{f_{\text {cl }}}$

where $R_{\text {ecl }}$ is intrinsic evaporative resistance $\left(\mathrm{m}^{2} \cdot \mathrm{Pa} / \mathrm{W}\right) ; R_{\mathrm{et}}$ is the total evaporative resistance of the CPC $\left(\mathrm{m}^{2} \cdot \mathrm{Pa} / \mathrm{W}\right) ; R_{\text {ea }}$ is evaporative resistance of 
Table 1 Four experimental scenarios

\begin{tabular}{|c|c|c|c|c|c|c|c|c|c|c|}
\hline \multirow[b]{2}{*}{ Scenarios } & \multirow[b]{2}{*}{ Clothing } & \multicolumn{4}{|c|}{ Characteristics of clothing materials } & \multicolumn{3}{|c|}{ Characteristics of CPC } & \multicolumn{2}{|c|}{ Activity state } \\
\hline & & Material & $\begin{array}{c}\text { Grammage/ } \\
\left(\mathrm{g} \cdot \mathrm{m}^{-2}\right)\end{array}$ & $\begin{array}{l}\text { Thermal } \\
\text { resistance/ } \\
\left(\mathrm{m}^{2} \cdot{ }^{\circ} \mathrm{C} \cdot \mathrm{W}^{-1}\right)\end{array}$ & $\begin{array}{c}\text { Evaporative } \\
\text { resistance/ } \\
\left(\mathrm{m}^{2} \cdot \mathrm{Pa} \cdot \mathrm{W}^{-1}\right)\end{array}$ & $\begin{array}{c}\text { Mass/ } \\
\mathrm{kg}\end{array}$ & $\begin{array}{c}\text { Thermal } \\
\text { insulation/ } \\
\text { clo }\end{array}$ & $\begin{array}{c}\text { Evaporative } \\
\text { resistance/ } \\
\left(\mathrm{m}^{2} \cdot \mathrm{Pa} \cdot \mathrm{W}^{-1}\right)\end{array}$ & $\begin{array}{l}\text { Speed/ } \\
\left(\mathrm{km} \cdot \mathrm{h}^{-1}\right)\end{array}$ & $\begin{array}{l}\text { Slope/ } \\
\%\end{array}$ \\
\hline A & $\mathrm{CF}$ & Cotton/carbon fabric & 549.8 & 0.0786 & 17.7 & 3.21 & 2.25 & 51.9 & 4 & 5 \\
\hline B & $\mathrm{PF}$ & $\begin{array}{l}\text { Polymer membrane } \\
\text { coated fabric }\end{array}$ & 138.2 & 0.0154 & 153.6 & 3.21 & 1.77 & 646.2 & 4 & 5 \\
\hline $\mathrm{C}$ & $\mathrm{RF}$ & Rubber composite fabric & 465.4 & 0.0307 & 135.0 & 4.74 & 1.71 & 727.4 & 4 & 5 \\
\hline $\mathrm{D}$ & RF & Rubber composite fabric & 465.4 & 0.0307 & 135.0 & 4.74 & 1.71 & 727.4 & 4 & 10 \\
\hline
\end{tabular}
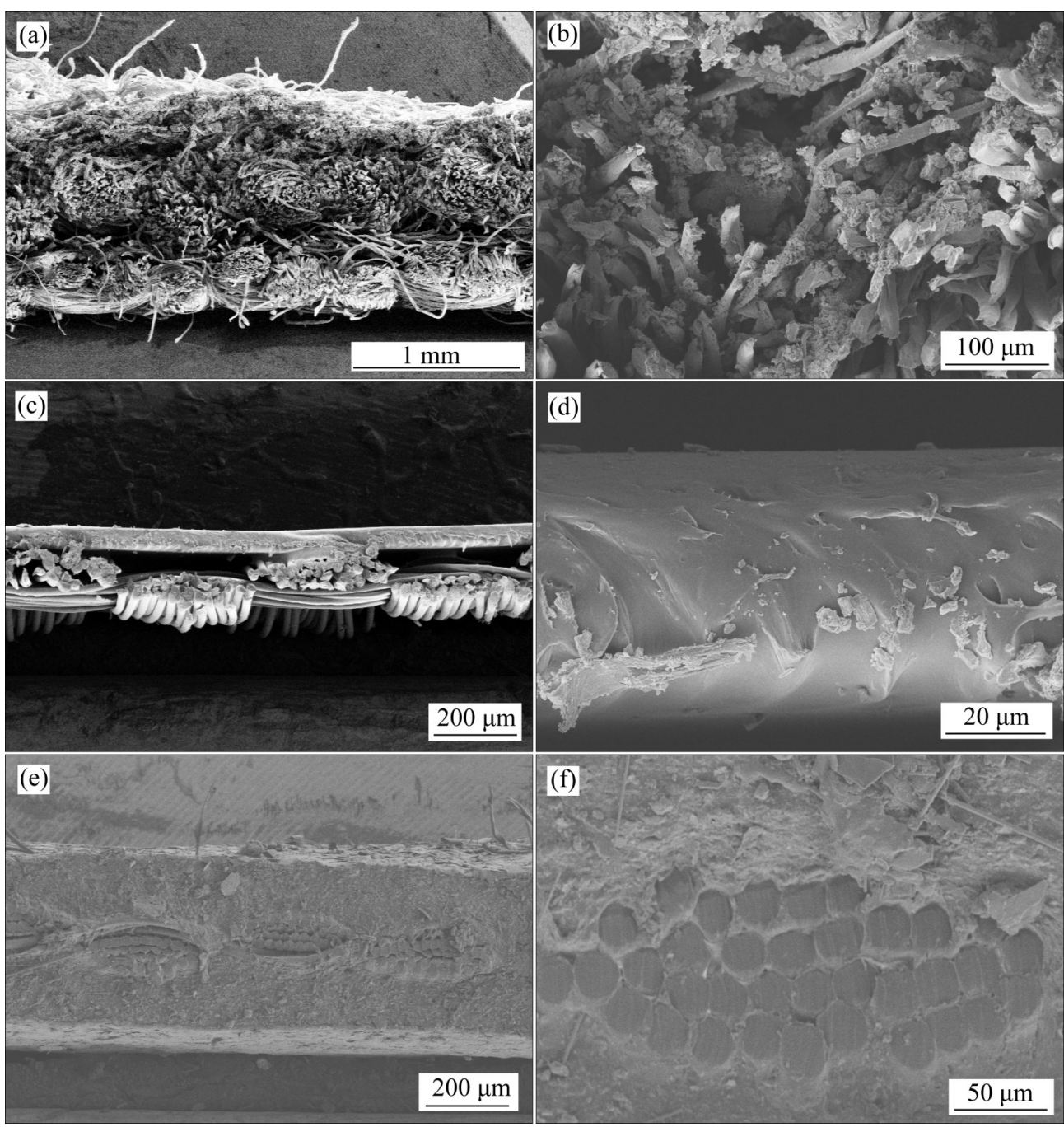

Figure 2 Cross-sectional morphology of clothing CF materials (a, b), clothing PF materials (c, d), and clothing RF materials $(e, f)$

the boundary air layer $\left(\mathrm{m}^{2} \cdot \mathrm{Pa} / \mathrm{W}\right) ; f_{\mathrm{cl}}$ is the clothing area factor (dimensionless).

Clothing area factor $\left(f_{\mathrm{c}}\right)$ was 1.60 , which was estimated according to ASTM F2370 [39].

Experimental scenarios are listed in Table 1. Scenarios A and B were used to compare the influence of thermal insulation and evaporative resistance on heat strain. The influence of CPC mass on heat strain was compared through Scenario B and Scenario C. Scenario C and Scenario D with different slopes were chosen to analyze the influence of activity intensity on heat strain.

\subsection{Participants}

Eight healthy males volunteered to participate in the study. The participants' personal information 
and physical characteristics were collected. The age, height, weight, body surface area and body mass index (BMI) are shown in Table 2. Participants were forbidden from strenuous exercise, smoking and drinking, and ensured adequate sleep time to achieve physical vitality the day before the experiment. The participants read the details of the experimental procedure and the notice of possible risks in advance, and signed the written consent. The study was approved by the State Key Laboratory of NBC Protection for Civilian Ethics Committee, China. All the experiments were carried out in random order and at the same time every two days, each participant needed to perform one of the four scenarios until all four scenarios were completed.

\subsection{Test procedure}

The human wear trials were performed in a climate chamber, where the air temperature was $(35 \pm 0.5){ }^{\circ} \mathrm{C}$, the relative humidity was $(60 \pm 5) \%$, and the wind speed was $(0.4 \pm 0.1) \mathrm{m} / \mathrm{s}$. Core temperature $\left(T_{\text {core }}\right)$ was measured using Cor-Temp capsule temperature sensor (HQ Inc., Palmetto, FL). Test procedure is shown in Figure 3. Three hours before the experiments, participants were given tepid water to swallow the core temperature capsule sensor. When the participants arrived at the laboratory, they sat quietly for $20 \mathrm{~min}$ and drank $300 \mathrm{~mL}$ of water. Skin temperature was measured using skin temperature sensors (YSI409b, 4000A, YSI Inc., Dayton, America) that were affixed to eight body sites (i.e., the forehead, left chest, right scapular, left shoulder, left forearm, left hand, right posterior thigh, left posterior calf) [40]. A heart rate recorder (Polar Team 2, Finland) was installed to continuously measure the heart rate. Then the experimental clothing was worn. Before entering the laboratory, the participants sat quietly for $5 \mathrm{~min}$ to allow their heart rate and body temperature to stabilize for a while. Then they started running on the treadmill according to the scenarios shown in Table 1 . The air temperature, relative humidity and wind speed of climate chamber were set to simulate hot summer condition in Guangdong province of China, and the activities in different scenarios represented the work of different intensities. Hence, the heat strain while wearing three kinds of CPC was studied in such a hot-humid environment.

The trials were ended if one of the following conditions was met: 1) The core temperature rose to $38.5{ }^{\circ} \mathrm{C}$; 2) The heart rate exceeded $180 \mathrm{~min}^{-1}$; 3) For the safety and health of the participants, the trial time should not exceed 60 min; 4) Fatigue or nausea (inability to persevere).

At the end of the activity, the clothes and recording equipment were removed. Then the participants went into the break room to rest and drink plenty of water. All experiments were supervised by medical professionals for safety.

\subsection{Parameters measurement and calculation}

The mean skin temperature $\left(T_{\text {skin }}\right)$ and heat storage $(S)$ were calculated with following equations [40]:

Table 2 Mean physical characters of the participants (mean value \pm standard deviation)

\begin{tabular}{cccccc}
\hline Number & Age $/$ year & Height $/ \mathrm{m}$ & Mass $/ \mathrm{kg}$ & Body surface $\operatorname{area} / \mathrm{m}^{2}$ & Body mass index $/\left(\mathrm{kg} \cdot \mathrm{m}^{-2}\right)$ \\
\hline 8 & $24.75 \pm 1.39$ & $1.71 \pm 0.03$ & $64.38 \pm 7.81$ & $1.76 \pm 0.04$ & $21.92 \pm 2.29$ \\
\hline
\end{tabular}

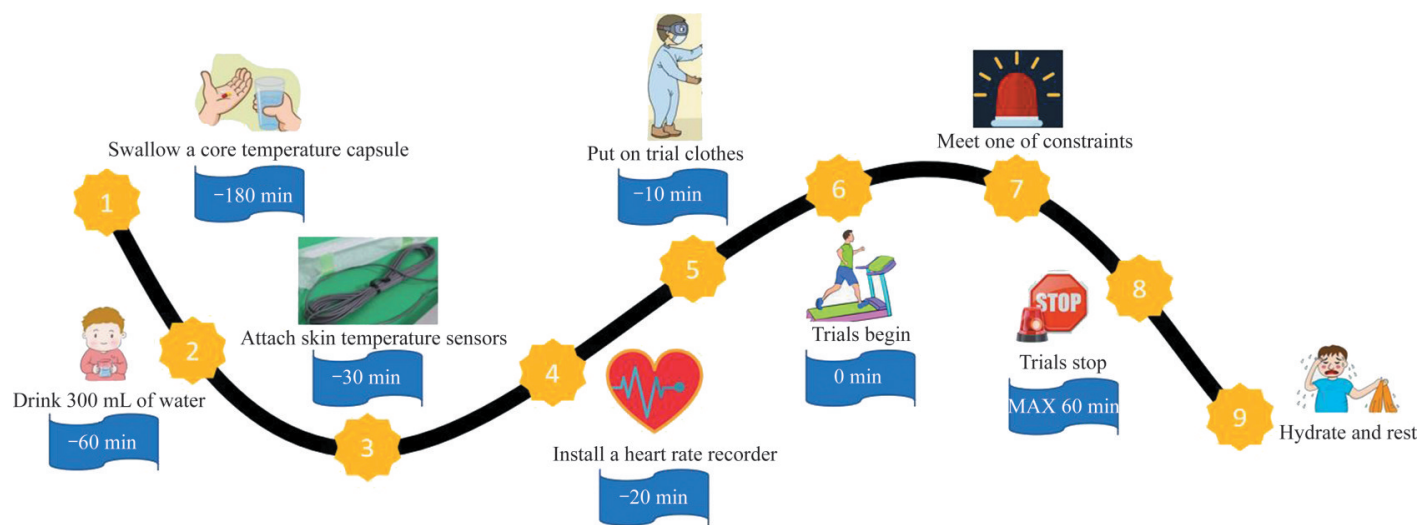

Figure 3 Test procedure 
$T_{\text {skin }}=0.07 T_{\text {forehead }}+0.175 T_{\text {left_chest }}+0.175 T_{\text {right_scapular }}+$ $0.07 T_{\text {left_shoulder }}+0.07 T_{\text {left_forearm }}+0.05 T_{\text {left_hand }}+$

$0.19 T_{\text {right_posterior_thigh }}+0.2 T_{\text {left_posterior_calf }}$

$S=c_{\mathrm{p}} W_{\text {nude,start }}\left(0.8 \Delta T_{\text {core }}+0.2 \Delta T_{\text {skin }}\right)$

where $c_{\mathrm{p}}, W_{\text {nude,start }} \Delta T_{\text {core }}$ and $\Delta T_{\text {skin }}$ are the specific heat capacity of human body $\left(c_{\mathrm{p}}=3.5 \mathrm{~kJ} /\left(\mathrm{kg} \cdot{ }^{\circ} \mathrm{C}\right)\right)$, nude body weight before the trials $(\mathrm{kg})$, changes in the core temperature and mean skin temperature over a certain time period $\left({ }^{\circ} \mathrm{C}\right)$, respectively.

\subsection{PHS model}

The PHS model predicts core temperature and skin temperature based on input parameters: air temperature, $35^{\circ} \mathrm{C}$; globe temperature, $35^{\circ} \mathrm{C}$; relative humidity, $60 \%$; air velocity, $0.4 \mathrm{~m} / \mathrm{s}$; emissivity of the reflective clothes, 0.97; permeability index, 0.38; stature, $1.71 \mathrm{~m}$; body mass, $64.38 \mathrm{~kg}$; walking speed, $4 \mathrm{~km} / \mathrm{h}$; posture, standing; acclimatized subjects, no; water consumption, no; exposure time, $30 \mathrm{~min}$. Clothing intrinsic thermal insulations were set to the scenarios in Table 1. The metabolic rates of Scenarios A, B, C and D were 254, 288, 334 and $367 \mathrm{~W} / \mathrm{m}^{2}$ respectively, which were estimated according to ISO7933 [41]. The PHS model predicted core and skin temperatures were compared to the results of human wear trials and the root mean square error (RMSE) of the PHS model predicted values and the mean SD of observed values were calculated. RMSE is defined as:

$\mathrm{RMSD}=\sqrt{\frac{1}{n} \sum_{i=1}^{n} T_{i}^{2}}$

where $T_{i}$ is the difference between the predicted and observed $T_{\text {core }}$ and $T_{\text {skin }}$ at each time point; and $n$ is the number of time points separated by $5 \mathrm{~min}$.

\subsection{Statistical analysis}

Shapiro-Wilk test was used to verify if the data conforms to the normal distribution. The analysis of variance of repeated measurements was applied to test whether there were significant differences due to different experimental conditions. Least significant difference Post Hoc test was performed to verify the significant difference in time and parameter(s) if there were significant differences between trial conditions. The level of significance was set at $p<0.05$. The data obtained in the first
$30 \mathrm{~min}$ were used to analyze core temperature, mean skin temperature, heart rate, and heat storage, because all participants had complete data in the first $30 \mathrm{~min}$, after which participants successively stopped the experiment.

\section{Results}

\subsection{Core temperature and mean skin temperature}

Temporal variations of core temperature in the four scenarios are shown in Figure 4. Comparing with the initial value, the core temperature increased by $0.3{ }^{\circ} \mathrm{C}$ in Scenario A, $0.6^{\circ} \mathrm{C}$ in Scenario B, $0.7^{\circ} \mathrm{C}$ in Scenario $\mathrm{C}$ and $1.2^{\circ} \mathrm{C}$ in Scenario $\mathrm{D}$ at the 30th min.

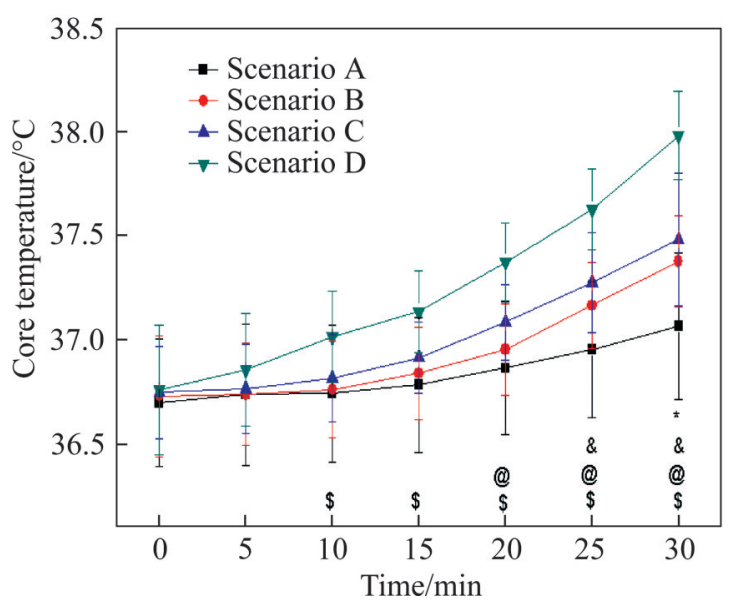

Figure 4 Changes of core temperature in four scenarios (*, $p<0.05$ (A vs. C), \$, $p<0.05$ (A vs. D), @, $p<0.05$ (B vs. D), $\&, p<0.05$ (C vs. D))

From the 10th min, there was a significant difference between Scenarios A and D. From the 20th min, the core temperature of Scenario D was significantly higher than that of Scenario B. From the 25th $\mathrm{min}$, there was a significant difference between Scenarios C and D. At the 30th min, the core temperature of Scenario $\mathrm{C}$ became significantly higher than that of Scenario A.

As shown in Figure 5, the mean skin temperature gradually increased in different experimental scenarios. From the beginning to the 30th min, the mean skin temperature of Scenarios A, B, C and D increased by 2.1, 2.8, 3.1 and $3.2^{\circ} \mathrm{C}$, respectively. From the 10th $\mathrm{min}$, there was a significant difference between the mean skin temperature of Scenario A and that of scenarios B, C and $\mathrm{D}$. At the 30th min, the mean skin temperature 


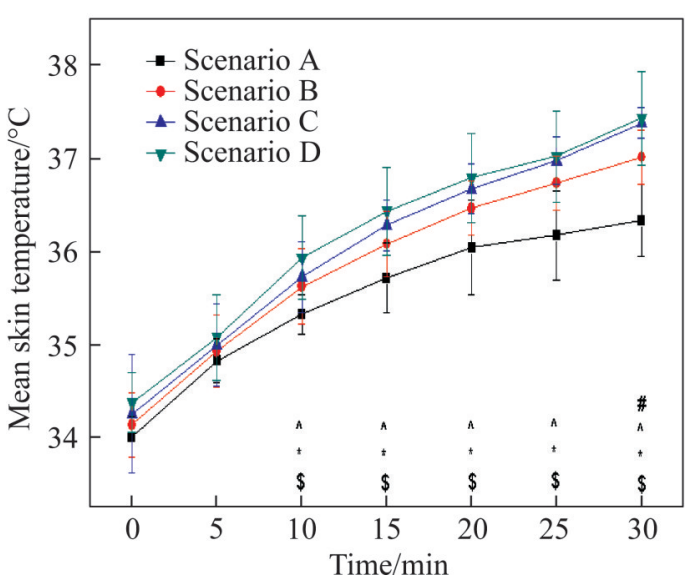

Figure 5 Changes of mean skin temperature in four scenarios ( ${ }^{\wedge}, p<0.05$ (A vs. B), ${ }^{*}, p<0.05$ (A vs. C), $\$, p<$ 0.05(A vs. D), \#, $\mathrm{p}<0.05$ (B vs. C))

in Scenario $C$ was significantly higher than that in Scenario B. During the 30-min experiment, there was no significant difference in mean skin temperature between Scenario C and Scenario D.

\subsection{Heart rate}

Figure 6 shows the temporal variations of heart rate in four scenarios. During the 30-min experiment, the heart rate increment of scenarios $\mathrm{A}$, $\mathrm{B}, \mathrm{C}$ and $\mathrm{D}$ was $42,55,69,75 \mathrm{~min}^{-1}$. From the 10th min, the heart rate of Scenario A was significantly lower than that of Scenario D. At the 20th min, the heart rate of Scenario $B$ was significantly different from that of Scenario D. Differences persisted throughout the experiments. From the 20th min, the heart rate of Scenario $C$ was significantly higher than that of Scenarios A and B.

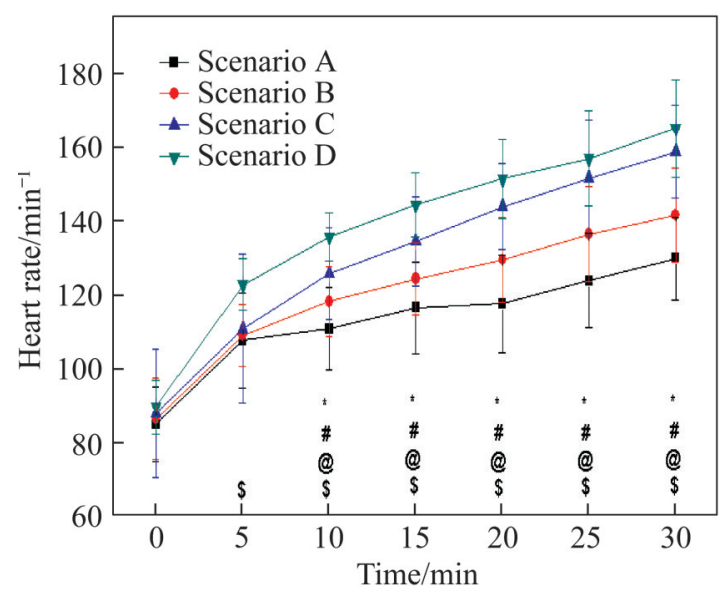

Figure 6 Heart rate changes in four scenarios $(*, p<0.05$ (A vs. C), \$, $p<0.05$ (A vs. D), \#, $p<0.05$ (B vs. C), @, $p<$ 0.05 (B vs. D))

\subsection{Heat storage}

As shown in Figure 7, the heat storage changes of Scenarios A, B, C and D increased by 161.67 , $252.15,269.93$ and $346.96 \mathrm{~kJ}$ during the 30 -min period, respectively.

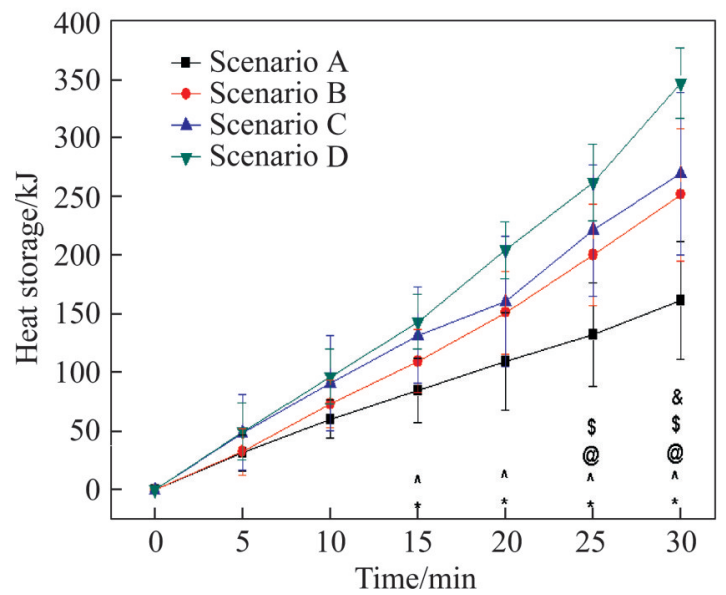

Figure 7 Changes of heat storage in four scenarios $\left({ }^{\wedge}, p<\right.$ 0.05(A vs. B), ${ }^{*}, p<0.05$ (A vs. C), \$, $p<0.05$ (A vs. D), @, $p<0.05$ (B vs. D), $\&, p<0.05(\mathrm{C}$ vs. D))

From the 15th $\min$, there were significant differences between Scenarios A and C, as well as Scenarios A and D. From the 25th min, there were significant differences between Scenarios A and B, and between Scenarios B and D. At the 30th min, there was a significant difference between scenarios $\mathrm{C}$ and D. There was no significant difference between the heat storage of Scenarios B and C.

\subsection{Activity duration}

In Scenario A, five out of eight participants ended the experiment at the 60th min. In Scenario $\mathrm{B}$, three participants ended the experiment after 60 min. In scenarios $C$ and $D$, no participant could walk for $60 \mathrm{~min}$. Tolerance time $\pm \mathrm{SD}$ for four

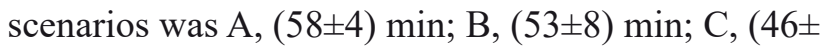
5) min; $\mathrm{D},(36 \pm 4)$ min (Figure 8$)$. The tolerance time of Scenario D was significantly shorter than that of the other three scenarios. The tolerance time of Scenario A was the longest, while the tolerance time of Scenario $C$ was significantly lower than that of Scenario B.

\subsection{Predicted heat strain by PHS model}

Figure 9 shows the differences between the observed and predicted values of core temperature 


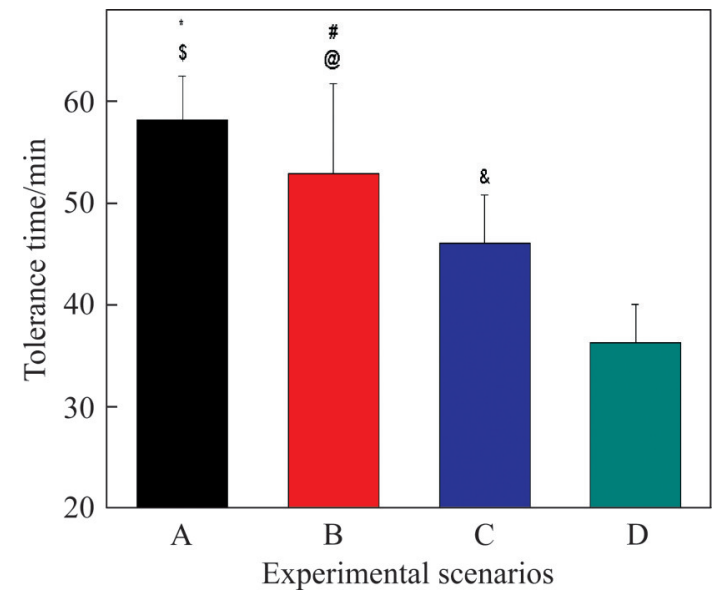

Figure 8 Tolerance time in four scenarios $(*, p<0.05$ (A vs. C), $\$, p<0.05$ (A vs. D), \#, $p<0.05$ (B vs. C), @, $p<0.05$ (B vs. D), \&, $p<0.05(\mathrm{C}$ vs. D))

and skin temperature in four scenarios. Table 3 shows the root mean square error (RMSE) of the PHS model predicted values and the mean SD of observed values. In all experimental scenarios, RMSE values were greater than SD values.
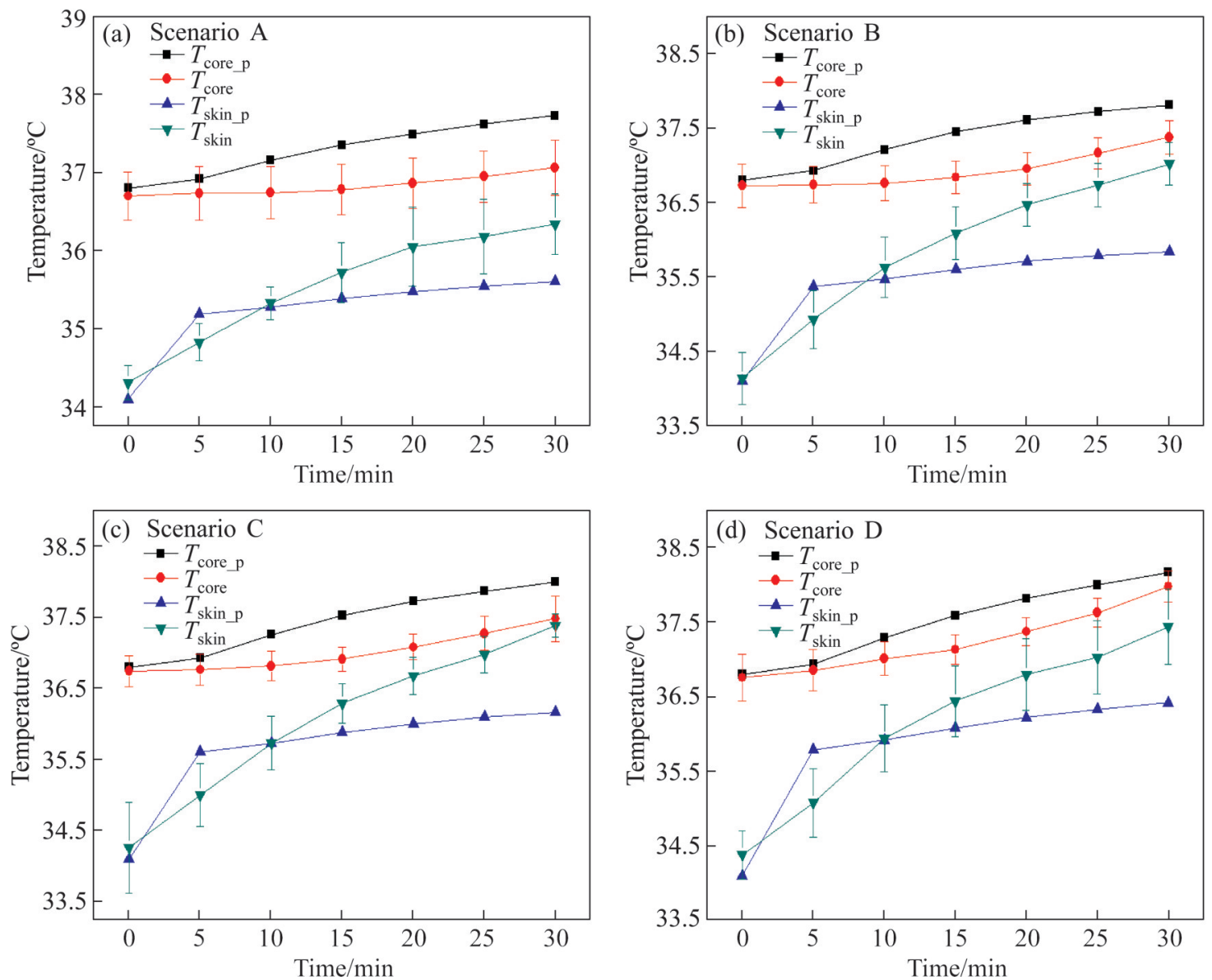

Figure 9 Core and skin temperature observations and PHS predictions in four scenarios $\left(T_{\text {core }}\right.$ : observed core temperature; $T_{\text {skin }}$ : observed skin temperature; $T_{\text {core } \_ \text {: }}$ predicted core temperature; $T_{\text {skin } \_ \text {: predicted skin temperature) }}$ 
Table 3 RMSE of PHS model predicted values and mean SD of observed values

\begin{tabular}{ccccccc}
\hline \multirow{2}{*}{$\begin{array}{c}\text { Experimental } \\
\text { scenario }\end{array}$} & \multicolumn{3}{c}{$T_{\text {core }}$} & & \multicolumn{2}{c}{$T_{\text {skin }}$} \\
\cline { 2 - 3 } \cline { 5 - 6 } & RMSE & SD & & RMSE & SD \\
\hline A & 0.51 & 0.33 & & 0.47 & 0.35 \\
B & 0.47 & 0.23 & & 0.69 & 0.34 \\
$\mathrm{C}$ & 0.48 & 0.22 & & 0.68 & 0.35 \\
$\mathrm{D}$ & 0.31 & 0.23 & & 0.61 & 0.45 \\
\hline
\end{tabular}

thermal barrier between the environment and body [7]. According to the mean skin temperature, the thermal insulation can only play the role of isolating the heat from the external environment in the first $5 \mathrm{~min}$. When the skin temperature exceeds $35^{\circ} \mathrm{C}$, the high thermal insulation affects the human body's heat dissipation to external environment. Evaporative resistance restricted the exchange of moisture and led to the reduction of evaporation heat transfer, which was the main factor causing heat strain in humid environment [43]. In this experiment, Scenario A with lower evaporative resistance had lower heat strain. Therefore, CPC with low thermal and evaporative resistance is necessary in hot-humid environment at the same level of protection.

Moderate increase in weight of CPC over a short period of time would have intensified the cardiovascular strain, but had less impact on core temperature and mean skin temperature. YAZDI et al [44] showed that an increase in the weight of CPC caused an increase in metabolism. DORMAN et al [4] developed a slope regression line based on human experiments, showing a $2.7 \%$ increase in metabolic rate for each additional kilogram of clothing weight. The differences in thermal insulation and evaporative resistance of scenarios B and $\mathrm{C}$ were small, and the changes of core temperature, mean skin temperature and heat storage were close. However, there were significant differences in heart rate and tolerance time. Compared with Scenario B, the heart rate of Scenario $\mathrm{C}$ was $17 \mathrm{~min}^{-1}$ higher at the 30th min of the experiment and the tolerance time was $7 \mathrm{~min}$ shorter. These indicated that the heart stress of Scenario C was greater than that of Scenario B. The reason was that the CPC of Scenario C was $47.66 \%$ heavier than that of Scenario B, and the body relied on an increased heart rate to speed up blood circulation to keep core temperature and mean skin temperature stable. COSTELLO et al [45] found that cardiovascular strain was the limiting factor in work tolerance when wearing heavy, multilayer, isolating CPC. Heart rate increased with the weight of the CPC, so the human body was more likely to feel tired and the tolerance time was shorter in Scenario C than in Scenario B. Within a certain range, an increase in the weight of the CPC could have a significant impact on heart rate and led to a shorter tolerance time. Meanwhile, what was interesting was that the weight increment did not significantly affect other physiological parameters.

This work also reconfirmed the intensity of activity and had a great influence on the heat strain in the hot-humid environment [46]. The same CPC was used in Scenarios C and D, but at different treadmill slopes. When the slope of Scenario $\mathrm{C}$ was $5 \%$, the core temperature increased by $0.7^{\circ} \mathrm{C}$ within $30 \mathrm{~min}$, while the core temperature increased by $1.2{ }^{\circ} \mathrm{C}$ while the slope of Scenario D was $10 \%$. The increase of body core temperature in this study was higher than the results of WEN et al [34]. They found that the participants walked on the treadmill for $30 \mathrm{~min}$ at a speed of $5.6 \mathrm{~km} / \mathrm{h}$ and a slope of $4 \%$ under the environmental conditions of $23{ }^{\circ} \mathrm{C}, 30 \%$ $\mathrm{RH}$, and $1.2 \mathrm{~m} / \mathrm{s}$ wind speed in an impermeable $\mathrm{CPC}$, causing the core temperature to rise by $0.7^{\circ} \mathrm{C}$. MARZAŁEK [47] also found that core temperature increased by $1.1^{\circ} \mathrm{C}$ after $30 \mathrm{~min}$ on a treadmill at a speed of $3 \mathrm{~km} / \mathrm{h}$ with an air temperature of $40{ }^{\circ} \mathrm{C}$, $30 \% \mathrm{RH}$ and wind speed of $0.2 \mathrm{~m} / \mathrm{s}$, for an impermeable CPC. In this study, comparing with Scenario C, the slope of Scenario D was higher and the intensity of activity was greater. Comparing with Scenario $\mathrm{C}$ in the 30th min of the experiment, the core temperature of Scenario D was $0.5^{\circ} \mathrm{C}$ higher, the heart rate was $8 \mathrm{~min}^{-1}$ higher, and the heat storage was $77 \mathrm{~kJ}$ higher. Therefore, the tolerance time of Scenario D is 10 min shorter than that of Scenario C. These results showed that in hot-humid environment, the heat strain became more severe when the slope increases from $5 \%$ to $10 \%$. However, the mean skin temperature of Scenario D was only $0.1{ }^{\circ} \mathrm{C}$ higher than that of Scenario $\mathrm{C}$ in the 30th min of the experiment, and there was no significant difference between the two scenarios 
during the whole experiment. This indicated that there was no significant difference in mean skin temperature, despite significant differences in other physiological parameters. These findings could help improve ways of predicting thermal comfort through skin temperature [48-50].

The PHS model provided conservative predictions of core and skin temperatures because the high thermal insulation CPC was used in the human wear trials. As shown in Figure 9, the predicted value of PHS was different from the observed value of physiological responses. In all experimental scenarios shown in Table 3, RMSE value was greater than SD value. In general, if RMSE is less than SD, the predicted value of PHS model is in good agreement with the observed value of human experiment [51]. On the other hand, when RMSE is greater than SD, the predicted value of PHS model is considered unreliable. The thermal insulation that could be applied to the PHS model was between 0.1 clo and 1 clo [41]. Therefore, it could be considered that the PHS prediction based on the human wear trials is not appropriate because of the condition is out of the range limit. WANG et al [33] pointed out that the PHS model is not accurate in predicting core and skin temperatures when the thermal insulation of clothing is greater than 1.0 clo. POTTER et al [29] also found that with the increase of thermal insulation of $\mathrm{CPC}$, the prediction accuracy of the heat strain decision aid (HSDA) for core temperature gradually decreased. Therefore, it is necessary to improve the prediction accuracy for high thermal insulation clothing. The thermal insulations of CPC used in this study were all higher than 1.0 clo, so the experimental results could be used to modify the heat strain prediction model.

The results of this study were limited to young men in the particular hot-humid environment (air temperature $(35 \pm 0.5){ }^{\circ} \mathrm{C}$, relative humidity $(60 \pm 5) \%$ and wind speed $((0.4 \pm 0.1) \mathrm{m} / \mathrm{s})$ in the lab for a period of $30 \mathrm{~min}$. There were significant differences in the physiological responses of men and women, young people and old people, as well as differences in laboratory conditions and in the field conditions $[52,53]$. Therefore, more researches are needed in the future to focus on the heat strain of people wearing CPC in different environmental conditions.

\section{Conclusions}

This paper studies the effects of clothing thermal properties on heat strain while wearing three kinds of CPC in hot-humid environment (air temperature $(35 \pm 0.5){ }^{\circ} \mathrm{C}$, relative humidity $(60 \pm 5) \%$ and wind speed $(0.4 \pm 0.1) \mathrm{m} / \mathrm{s})$. The results showed that the physiological responses of human body were significantly affected by the clothing thermal properties and activity intensity in the hot-humid environment. CPC with low thermal and evaporative resistance should be worn in hot-humid environment at the same level of protection. The moderate increase in weight of $\mathrm{CPC}$ over a short period of timed could aggravate the cardiovascular strain, but has little effect on core temperature and mean skin temperature. The prediction results of the heat strain model were not applicable to the CPC with high thermal insulation. In order to improve the prediction accuracy, the model needs to be further modified. New materials with lower thermal and evaporative resistance and less weight are necessary to alleviate the heat strain in hot-humid environments, and improved or new models need to be studied based on further research to predict and prevent the heat strain.

\section{Contributors}

The overarching research goals were developed by ZHENG Xiao-hui, DING Song-tao, and ZHANG Chuan-kun. LIANG Guo-jie and WANG Xin-bo analyzed the data. ZHANG Chuan-kun and CHEN Ying analyzed the calculated results. The initial draft of the manuscript was written by ZHENG Xiao-hui, and ZHANG Chuan-kun. All authors replied to reviewers' comments and revised the final version.

\section{Conflict of interest}

ZHANG Chuan-kun, CHEN Ying, LIANG Guo-jie, WANG Xin-bo, ZHENG Xiao-hui, and DING Song-tao declare that they have no conflict of interest. 


\section{References}

[1] VAN WELY E. Current global standards for chemical protective clothing: How to choose the right protection for the right job? [J]. Industrial Health, 2017, 55(6): 485-499. DOI: $10.2486 /$ indhealth.2017-0124.

[2] SCHLADER Z J, TEMPLE J L, HOSTLER D. Exercise in personal protective equipment in a hot, humid environment does not affect risk propensity [J]. Temperature (Austin), 2016, 3(2): 262-270. DOI: 10.1080/23328940.2016.1148526.

[3] XU Xiao-jiang, GONZALEZ J A, SANTEE W R, BLANCHARD L A, HOYT R W. Heat strain imposed by personal protective ensembles: Quantitative analysis using a thermoregulation model [J]. International Journal of Biometeorology, 2016, 60(7): 1065 - 1074. DOI: 10.1007/ s00484-015-1100-0.

[4] DORMAN L E, HAVENITH G. The effects of protective clothing on energy consumption during different activities [J]. European Journal of Applied Physiology, 2009, 105(3): 463-470. DOI: 10.1007/s00421-008-0924-2.

[5] QIN Xue-mei, SHU Kong-liang, WANG Mi, CHEN Wentao, HUANG Mei, YANG Ai-ping, ZHOU Yun, ZHANG Yan, JU Yu-meng, LIU Ji-yang. Mental health status of patients with coronavirus disease 2019 in Changsha [J]. Journal of Central South University: Medical Sciences, 2020, 45(6): 657 - 664. DOI: $10.11817 /$ j. issn. 1672-7347.2020. 200347. (in Chinese)

[6] LEI Yong-peng, WANG Qi-chen, PENG Sheng-jie, RAMAKRISHNA S, ZHANG Dou, ZHOU Ke-chao. Electrospun inorganic nanofibers for oxygen electrocatalysis: Design, fabrication, and progress [J]. Advanced Energy Materials, 2020, 10(45): 1902115. DOI: 10.1002/aenm. 201902115.

[7] MCLELLAN T M, DAANEN H A, CHEUNG S S. Encapsulated environment [J]. Comprehensive Physiology, 2013, 3(3): 1363-1391. DOI: 10.1002/cphy.c130002.

[8] KUWABARA K, HAMADA Y, KUBOTA H. Analysis of sweating efficiency and its effects on the heat strain alleviation of clothed subjects [J]. Physiological Reports, 2021, 9(1): e14694. DOI: 10.14814/phy2.14694.

[9] MALEY M J, MINETT G M, BACH A J E, STEWART K L, STEWART I B. Extending work tolerance time in the heat in protective ensembles with pre- and per-cooling methods [J]. Applied Ergonomics, 2020, 85: 103064. DOI: 10.1016/j. apergo.2020.103064

[10] HANCOCK P A, VASMATZIDIS I. Human occupational and performance limits under stress: The thermal environment as a prototypical example [J]. Ergonomics, 1998, 41(8): 1169-1191. DOI: 10.1080/001401398186469.

[11] BROWN P I, MCLELLAN $\mathrm{T}$ M, LINNANE D M, WILKINSON D M, RICHMOND V L, HORNER F E, BLACKER S D, RAYSON M P. Influence of hydration volume and ambient temperature on physiological responses while wearing CBRN protective clothing [J]. Ergonomics, 2010, 53(12): 1484 - 1499. DOI: 10.1080/ 00140139.2010.527017.

[12] YANG Jie, WENG Wen-guo, ZHANG Bao-ting. Experimental and numerical study of physiological responses in hot environments [J]. Journal of Thermal Biology, 2014, 45: 54-61. DOI: 10.1016/j.jtherbio.2014.07.010.

[13] JOVANOVIĆ D, KARKALIĆ R, ZEBA S, PAVLOVIĆ M, RADAKOVIĆ $\mathrm{S}$ S. Physiological tolerance to uncompensated heat stress in soldiers: Effects of various types of body cooling systems [J]. Vojnosanitetski Pregled, 2014, 71(3): 259-264. DOI: 10.2298/vsp120731045j.

[14] LEE J, VENUGOPAL V, LATHA P K, ALHADAD S B, LEOW C H W, DE GOH N Y, TAN E, KJELLSTROM T, MORABITO $\mathrm{M}$, et al. Heat stress and thermal perception amongst healthcare workers during the COVID-19 pandemic in India and Singapore [J]. International Journal of Environmental Research and Public Health, 2020, 17(21): 8100. DOI: 10.3390/ijerph17218100.

[15] HOLMÉR I. Protective clothing and heat stress [J]. Ergonomics, 1995, 38(1): 166-182. DOI: 10.1080/0014013 9508925093.

[16] HOLMÉR I. Protective clothing in hot environments [J]. Industrial Health, 2006, 44(3): 404 - 413. DOI: 10.2486/ indhealth.44.404.

[17] LEE S, OBENDORF S K. Barrier effectiveness and thermal comfort of protective clothing materials $[\mathrm{J}]$. The Journal of the Textile Institute, 2007, 98(2): 87-98. DOI: 10.1533/joti. 2005.0143.

[18] BHUIYAN M A R, WANG Li-jing, SHAID A, JAHAN I, SHANKS $\mathrm{R}$ A. Silica aerogel-integrated nonwoven protective fabrics for chemical and thermal protection and thermophysiological wear comfort [J]. Journal of Materials Science, 2020, 55(6): 2405-2418. DOI: 10.1007/s10853-01904203-2.

[19] ROSSI R. Interactions between protection and thermal comfort[M]//Textiles for Protection. Amsterdam: Elsevier, 2005: 233-260. DOI: 10.1533/9781845690977.1.233.

[20] RISSANEN S, JOUSELA I, JEONG J R, RINTAMÄKI H. Heat stress and bulkiness of chemical protective clothing impair performance of medical personnel in basic lifesaving tasks [J]. Ergonomics, 2008, 51(7): $1011-1022$. DOI: 10. 1080/00140130701813160.

[21] ASHDOWN S P. Improving body movement comfort in apparel[M]/Improving Comfort in Clothing. Amsterdam: Elsevier, 2011: 278 - 302. DOI: 10.1533/9780857090645. 2.278 .

[22] ZHENG Jie, CHEN Liang, LI Bai-zhan, CHEN Lu. Indoor thermal comfort studies based on physiological parameter measurement and questionnaire investigation [J]. Journal of Central South University of Technology, 2006, 13(4): 404407. DOI: 10.1007/s11771-006-0057-x.

[23] LI Nan, LUO Guo-zhi, LI Bai-zhan, HUANG Yan-qi. Impact of light-weight external thermal insulation materials on building surrounding thermal environment in summer $[\mathrm{J}]$. Journal of Central South University, 2012, 19(6): 1639 1644. DOI: 10.1007/s11771-012-1187-y.

[24] ZHANG Xue-jun, YUAN Zhen-hua, YANG Rui-xin, HE Yilin, QIN Ying-lin, XIAO Si, HE Jun. A review on spatial selfphase modulation of two-dimensional materials [J]. Journal of Central South University, 2019, 26(9): 2295-2306. DOI: 10.1007/s11771-019-4174-8.

[25] HABIBI P, MORADI G, DEHGHAN H, MORADI A, HEYDARI A. The impacts of climate change on occupational heat strain in outdoor workers: A systematic 
review [J]. Urban Climate, 2021, 36: 100770. DOI: 10.1016/j. uclim.2021.100770.

[26] LIU Hong, TAN Qing, LI Bai-zhan, TAN Mei-lan, MA Xiaolei. Impact of cold indoor thermal environmental conditions on human thermal response [J]. Journal of Central South University of Technology, 2011, 18(4): 1285 - 1292. DOI: 10.1007/s11771-011-0834-z.

[27] YANG Hua, CHEN Wan-he, KONG Xiang-fei, RONG Xian. Fabrication, property characterization and thermal performance of composite phase change material plates based on tetradecanol-myristic acid binary eutectic mixture/ expanded perlite and expanded vermiculite for building application [J]. Journal of Central South University, 2019, 26 (9): 2578-2595. DOI: 10.1007/s11771-019-4196-2.

[28] WANG F, GAO C, KUKLANE K, HOLMÉR I. Effects of various protective clothing and thermal environments on heat strain of unacclimated men: The PHS (predicted heat strain) model revisited [J]. Industrial Health, 2013, 51(3): 266-274. DOI: $10.2486 /$ indhealth.2012-0073.

[29] POTTER A W, HUNT A P, CADARETTE B S, FOGARTY A, SRINIVASAN S, SANTEE W R, BLANCHARD L A, LOONEY D P. Heat Strain Decision Aid (HSDA) accurately predicts individual-based core body temperature rise while wearing chemical protective clothing $[\mathrm{J}]$. Computers in Biology and Medicine, 2019, 107: 131-136. DOI: 10.1016/j. compbiomed.2019.02.004.

[30] D'AMBROSIO ALFANO F R, PALELLA B I, RICCIO G, MALCHAIRE J. On the effect of thermophysical properties of clothing on the heat strain predicted by PHS model [J]. The Annals of Occupational Hygiene, 2016, 60(2): 231-251. DOI: 10.1093/annhyg/mev070.

[31] HAVENITH G. Individualized model of human thermoregulation for the simulation of heat stress response [J]. Journal of Applied Physiology (Bethesda, Md, 2001, 90 (5): 1943-1954. DOI: 10.1152/jappl.2001.90.5.1943.

[32] DU Chen-qiu, LI Bai-zhan, LI Yong-qiang, XU Meng-nan, YAO Run-ming. Modification of the Predicted Heat Strain (PHS) model in predicting human thermal responses for Chinese workers in hot environments [J]. Building and Environment, 2019, 165: 106349. DOI: 10.1016/j. buildenv. 2019.106349.

[33] WANG Fa-ming, KUKLANE K, GAO Chuan-si, HOLMÉR I. Can the PHS model (ISO7933) predict reasonable thermophysiological responses while wearing protective clothing in hot environments? [J]. Physiological Measurement, 2011, 32(2): 239 - 249. DOI: 10.1088/0967$3334 / 32 / 2 / 007$

[34] WEN Shu-qin, PETERSEN S, MCQUEEN R, BATCHELLER J. Modelling the physiological strain and physical burden of chemical protective coveralls [J]. Ergonomics, 2015, 58(12): 2016-2031. DOI: 10.1080/00140 139.2015.1051595.

[35] MONTAIN S J, SAWKA M N, CADARETTE B S, QUIGLEY M D, MCKAY J M. Physiological tolerance to uncompensable heat stress: Effects of exercise intensity, protective clothing, and climate [J]. Journal of Applied Physiology, 1994, 77(1): 216 - 222. DOI: 10.1152/jappl. 1994.77.1.216

[36] XU Xiao-jiang, RIOUX T P, POMERANTZ N, TEW S, BLANCHARD L A. Heat strain in chemical protective ensembles: Effects of fabric thermal properties [J]. Journal of Thermal Biology, 2019, 86: 102435. DOI: 10.1016/j. jtherbio.2019.102435.

[37] LEVINE L, JOHNSON R F, TEAL W B, et al. Heat strain evaluation of chemical protective garments[J]. Aviation Space and Environmental Medicine, 2001, 72, (4): 329-335.

[38] ASTM Standard F1291-10. Standard test method for measuring the thermal insulation of clothing using a heated manikin [S]. 2010.

[39] ASTM Standard F2370-10. Standard test method for measuring the evaporative resistance of clothing using a sweating manikin, astm [S]. 2010.

[40] WANG Fa-ming, CHOW C S W, ZHENG Qing, KE Ying, YANG Bin, ZHENG Xiao-hui, NOOR N, ZHANG Qi-ming, ZHANG Chuan-kun. On the use of personal cooling suits to mitigate heat strain of mascot actors in a hot and humid environment [J]. Energy and Buildings, 2019, 205: 109561. DOI: 10.1016/j.enbuild.2019.109561.

[41] Swiss Standards. Ergonomics of the thermal environmentanalytical determination and interpretation of heat stress using calculation of the predicted heat strain [S]. 2004.

[42] FU M, WENG W G, YUAN H Y. Quantitative assessment of the relationship between radiant heat exposure and protective performance of multilayer thermal protective clothing during dry and wet conditions [J]. Journal of Hazardous Materials, 2014, 276: 383-392. DOI: 10.1016/j.jhazmat.2014.05.056.

[43] EPSTEIN Y, HELED Y, KETKO I, MUGINSHTEIN J, YANOVICH R, DRUYAN A, MORAN D S. The effect of air permeability characteristics of protective garments on the induced physiological strain under exercise-heat stress [J]. The Annals of Occupational Hygiene, 2013, 57(7): 866-874. DOI: 10.1093/annhyg/met003.

[44] YAZDI M M, SHEIKHZADEH M, CHAVOSHI S E. Modeling the performance of a PCM cooling vest considering its side effects [J]. International Journal of Clothing Science and Technology, 2015, 27(4): 573-586. DOI: 10.1108/ijcst-01-2014-0018.

[45] COSTEllo J T, STEWART K L, STEWART I B. The effects of metabolic work rate and ambient environment on physiological tolerance times while wearing explosive and chemical personal protective equipment [J]. BioMed Research International, 2015, 2015: 1-7. DOI: 10.1155/2015/ 857536.

[46] MClellan T M, POPE J I, CAIN J B, CHEUNG S S. Effects of metabolic rate and ambient vapour pressure on heat strain in protective clothing [J]. European Journal of Applied Physiology and Occupational Physiology, 1996, 74 (6): 518-527. DOI: 10.1007/BF02376767.

[47] MARSZAŁEK A, BARTKOWIAK G, ŁĘŻAK K. Physiological effects of a modification of the construction of impermeable protective clothing [J]. International Journal of Occupational Safety and Ergonomics, 2009, 15(1): 61-73. DOI: 10.1080/10803548.2009.11076789.

[48] YANG Jie, WENG Wen-guo, FU Ming. A coupling system to predict the core and skin temperatures of human wearing protective clothing in hot environments [J]. Applied Ergonomics, 2015, 51: $363-369$. DOI: 10.1016/j. apergo. 2015.06.002.

[49] WELLES A P, XU Xiao-jiang, SANTEE W R, LOONEY D P, BULLER M J, POTTER A W, HOYT R W. Estimation of 
core body temperature from skin temperature, heat flux, and heart rate using a Kalman filter [J]. Computers in Biology and Medicine, 2018, 99: 1-6. DOI: 10.1016/j. compbiomed. 2018.05.021.

[50] POTTER A W, BLANCHARD L A, FRIEDL K E, CADARETTE B S, HOYT R W. Mathematical prediction of core body temperature from environment, activity, and clothing: The heat strain decision aid (HSDA) [J]. Journal of Thermal Biology, 2017, 64: 78-85. DOI: 10.1016/j.jtherbio. 2017.01.003

[51] BOGERD N, PSIKUTA A, DAANEN H A, ROSSI R M. How to measure thermal effects of personal cooling systems:
Human, thermal manikin and human simulator study [J]. Physiological Measurement, 2010, 31(9): 1161-1168. DOI: 10.1088/0967-3334/31/9/007.

[52] COSTELLO J T, BIEUZEN F, BLEAKLEY C M. Where are all the female participants in sports and exercise medicine research? [J]. European Journal of Sport Science, 2014, 14(8): 847-851. DOI:10.1080/17461391.2014.911354.

[53] KENNEY W L, HODGSON J L. Heat tolerance, thermoregulation and ageing [J]. Sports Medicine, 1987, 4(6): 446-456. DOI: 10.2165/00007256-198704060-00004.

(Edited by YANG Hua)

\section{中文导读}

\section{热湿环境中化学防护服热应激研究: 服装热性能的影响}

摘要: 在热湿环境中, 人员穿着化学防护服时会产生危险性极高的严重热应激反应。缓解人员热应激 需要材料学、人机工效学、生理学和传热学等学科交叉协同发展。本文目的是研究服装、生理反应和 环境条件之间的关系。在温度 $(35 \pm 0.5){ }^{\circ} \mathrm{C}$ 和相对湿度 $(60 \pm 5) \%$ 的环境中, 8 名被试人员穿着三种化学防 护服, 在跑台上以 $4 \mathrm{~km} / \mathrm{h}$ 的速度运动(运动坡度分别为 $5 \%$ 和 $10 \%$ ), 记录并分析被试人员体核温度、平 均皮肤温度、心率、热蓄积和耐受时间。研究表明, 在热湿环境中, 服装热性能和运动强度对人体生 理反应有显著影响, 研究结果可为进一步发展化学防护服及热应激模型提供参考。在热湿环境中为缓 解人员热应激, 需要具有更低热阻、湿阻和更轻重量的新型材料。

关键词: 热应激; 化学防护服; 热阻; 湿阻; 热湿环境 